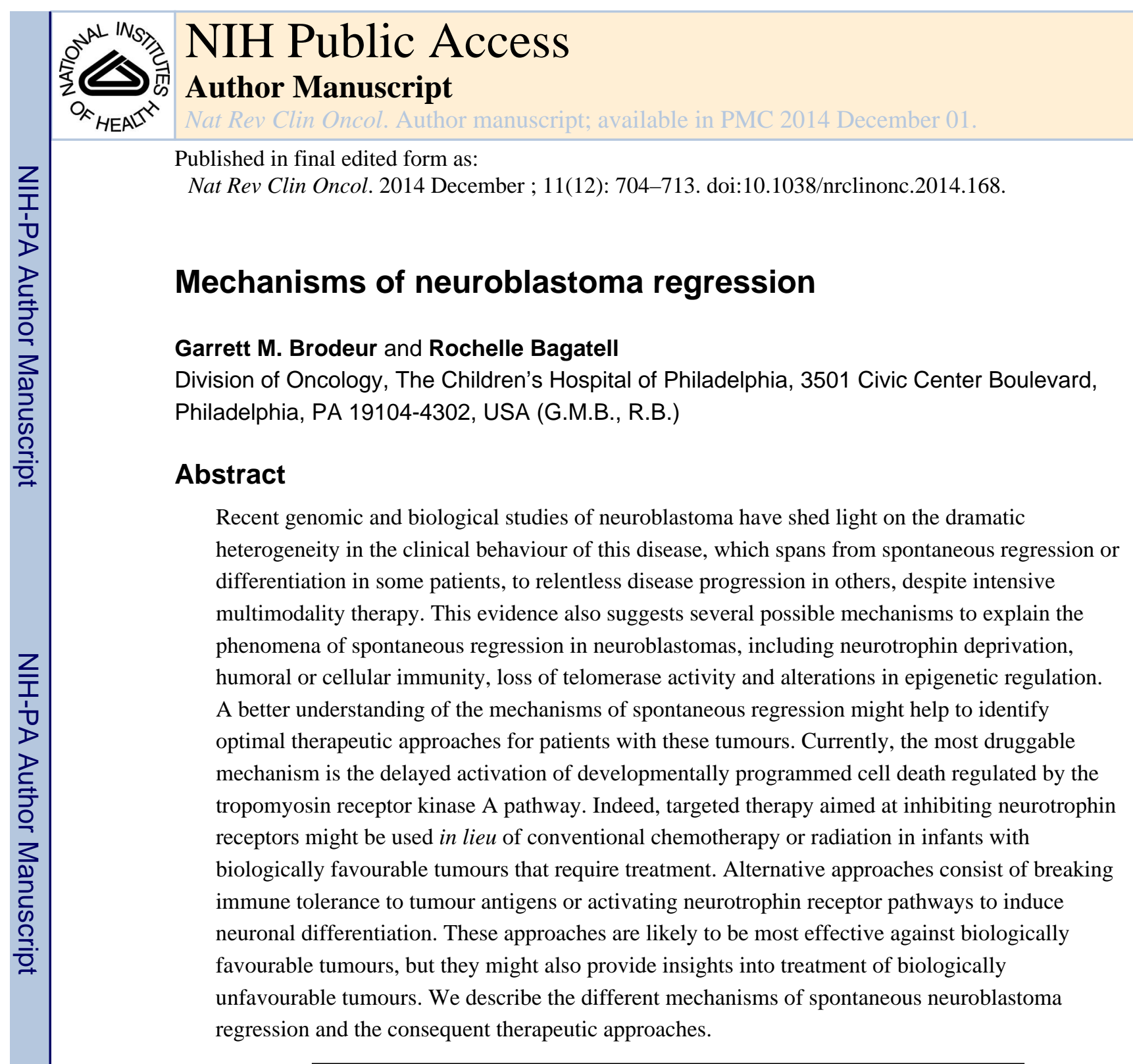

\title{
Introduction
}

Neuroblastoma is the most common extracranial solid tumour of children; it accounts for 8$10 \%$ of childhood cancers in the USA and Europe. ${ }^{1-4}$ Neuroblastomas in children 18 months of age or older are frequently unresectable or metastatic, require intensive multimodality therapy and are associated with a 40-50\% survival rate. ${ }^{1,2,5}$ However, neuroblastomas in children under 18 months of age behave very differently. Most infants, even with metastatic disease, can be cured with moderate-intensity chemotherapy, and some patients with a special pattern of metastasis have a high likelihood of undergoing spontaneous regression without chemotherapy ${ }^{6-10}$ Indeed, the prevalence of spontaneous regression has been

(C) 2014 Macmillan Publishers Limited. All rights reserved

Correspondence to: G.M.B. brodeur@e-mail.chop.edu.

Competing interests

The authors declare no competing interests.

Author contributions

G.M.B. and R.B. researched data and discussed content for article, wrote, reviewed and edited the manuscript before submission. 
documented by mass-screening programmes undertaken in Japan, Quebec and Europe. ${ }^{11-14}$ Furthermore, children (and adults) can present with localized, benign ganglioneuromas, which likely represent neuroblastic tumours that have become differentiated. ${ }^{15-19}$ The exact mechanisms responsible for spontaneous regression (and differentiation) are uncertain, but several plausible mechanisms have been proposed to explain these phenomena. ${ }^{6-10}$ In this Review, we explore the current understanding of the genomic, biological and immunological mechanisms that underlie spontaneous regression, and possible approaches to therapy.

\section{Genetic predisposition}

About $1-2 \%$ of patients with neuroblastoma have a family history of this disease. ${ }^{20-23}$ Two genes have been identified, $A L K$ and $P H O X 2 B$, that account for $\sim 80 \%$ of hereditary neuroblastoma. Specifically, several groups have shown that activating mutations in $A L K$ are responsible for $\sim 75 \%$ cases of hereditary neuroblastoma. ${ }^{20,24-26}$ Neuroblastomas also occur in patients with congenital central hypoventilation syndrome (Ondine's curse), and inactivating mutations of $P H O X 2 B$ are present in most of these patients, accounting for another $5 \%$ of hereditary cases..$^{22,27,28}$

Genome-wide association studies have identified several gene polymorphisms associated with a low, but significant risk of neuroblastoma, which include BARD1, LMO1, and $L I N 28 B$ among others. ${ }^{29-33}$ Genetically engineered mouse models that develop neuroblastoma are available, and include $T H-M Y C N,{ }^{34} M D M 2+M Y C N,{ }^{35} A L K+M Y C N,{ }^{36}$ $A L K,{ }^{37}$ and $L I N 28 B .{ }^{38}$ However, no cases of hereditary neuroblastoma have been associated with germline mutations of genes other than $A L K$ and $P H O X 2 B$, and none has been associated with spontaneous regression.

\section{Subtypes of neuroblastomas}

Several genomic alterations have been identified in neuroblastomas that generate tumours with distinct genotypes characterized by different patterns of clinical behaviour (Figure 1). ${ }^{15}$ Neuroblastomas can be divided into three major subtypes based on cytogenetic profilessubtype 1,2A and 2B. Subtype 1 is characterized by numerical chromosome alterations resulting in hyperdiploidy or near triploidy, but with few if any segmental chromosomal abnormalities (SCAs). ${ }^{39,40}$ High expression levels of the tropomyosin receptor kinase (Trk) A is common to almost all subtype 1 tumours. Patients with these tumours have favourable features (such as young age and low tumour stage) and outcomes. Subtype 2 is characterized by near diploidy and recurrent SCAs. Many of these tumours have an unbalanced gain of the chromosome 17q, and most overexpress both TrkB and its ligand. However, this subtype can be further subdivided into subtype $2 \mathrm{~A}$, which frequently has segmental loss of chromosomes 3p, 4p, and/or 11q; and subtype 2B, which has deletion of chromosome 1p and/or MYCN amplification. Neuroblastoma of subtypes $2 \mathrm{~A}$ and $2 \mathrm{~B}$ are associated with older age, advanced tumour stage and a worse clinical outcome, with subtype 2B tumours being the most aggressive (Figure 1). ${ }^{15}$

Deep-sequencing studies of neuroblastoma exomes or whole-genome analysis have identified relatively few additional gene mutations that were not otherwise known to have a role in this disease. In addition to $M Y C N$ amplification (found in $22 \%$ of primary tumours), 
activating mutations or rearrangements of $A L K$ were found in $8-10 \%$ of sporadic tumours. ${ }^{41}$ Furthermore, mutations in ATRX, ARIDIA, ARIDIB, MYCN, PTPN11 and NRAS were found in $1-3 \%$ of cases (Table 1). ${ }^{15,41-44}$ Oncogenic activation of FOXR1 by $11 \mathrm{q} 23$ intrachromosomal deletion-fusions has been identified in a few neuroblastoma cases (Table 1) ${ }^{45}$ In general, these alterations are associated with high-risk disease, and ATRX mutations are more common in older patients. ${ }^{42}$ However, with the exception of hyperdiploidy and/or near triploidy with numerical chromosome alterations, no specific genomic changes are associated with low-risk disease or with disease regression. ${ }^{46-48}$ The relative paucity of mutations in neuroblastomas, especially in patients with low-risk tumours, suggests that copy number, gene dosage and/or epigenetic regulation are probably important mechanisms in regulating gene expression and tumour cell behaviour.

\section{Neuroblastoma-spontaneous regression}

\section{Historical descriptions}

Spontaneous regression of cancer is defined as the decrease in size or disappearance of a primary tumour or metastatic disease without therapeutic intervention. Neuroblastoma is consistently regarded as one of the most common cancers to undergo spontaneous regression, in addition to carcinoma of the kidney, malignant melanoma, choriocarcinoma, and lymphoid malignancies. ${ }^{49-52}$ However, the prevalence of neuroblastoma regression was unknown until recently.

Beckwith and Perrin studied the adrenal glands of infants less than 3 months old who were not known to have neuroblastoma and had died for various reasons. They found microscopic foci of neuroblastic cells in the adrenal glands of 1 out of 40 infants studied, and they suggested the term "in situ neuroblastoma" to describe this phenomenon. ${ }^{53}$ The researchers proposed that these neuroblastic nodules might eventually evolve into clinically detectable neuroblastoma. Based on this assumption and the normal prevalence of clinically detected neuroblastoma of about 1 in 8,000 live births, the researchers inferred that the prevalence of spontaneous regression of neuroblastoma was about 200-fold higher than clinically detected disease. However, subsequently others have studied the adrenal glands of foetuses that were spontaneously aborted, and found that similar neuroblastic foci were present in all foetuses, with a peak time of appearance between 16-20 weeks of gestation, and after that these foci gradually disappeared. ${ }^{54,55}$ Thus, it is likely that neuroblastic rests seen in the first study were not insipient nodules of malignant neuroblastoma in situ, but rather the residual elements of normal sympathoadrenal development. Nevertheless, these normal neuroblastic nodules might contain the cells from which adrenal neuroblastomas arise.

\section{Neuroblastoma stage 4S}

The phenomenon of spontaneous regression of neuroblastoma was already known, but it was further highlighted by Evans and D'Angio who identified a specific pattern of metastatic spread called stage IVS. ${ }^{56,57}$ Infants with stage IVS generally had small primary tumours with dissemination limited to the liver and skin, with minimal bone marrow involvement. These patients were noted to have a very good prognosis, and some did well even in the absence of any tumour-specific therapy. ${ }^{56,57}$ This is in contrast to patients over $12-18$ 
months of age with a different pattern of metastatic disease that included bone lesions and more-extensive marrow involvement. Patients with the latter pattern of metastatic disease generally had a poor prognosis. ${ }^{58,59}$ Later, the definition of stage IVS was refined as stage $4 \mathrm{~S}$ by the International Neuroblastoma Staging System (INSS) ${ }^{60,61}$ INSS stage $4 \mathrm{~S}$ was restricted to infants aged less than 12 months at diagnosis, with small primary tumours (INSS stage 1 or 2), and with less than $10 \%$ marrow involvement. The most recent staging system iteration is called the International Neuroblastoma Risk Group Staging System (INRGSS), and this stage is referred to as stage MS (M for metastatic, $\mathrm{S}$ for special); ${ }^{62}$ we will refer to this stage as $4 \mathrm{~S}$ in this Review. However, it is clear that spontaneous regression is not restricted to this stage or subset of patients, as regression can be seen in infants with any stage of disease if they have biologically favourable tumours. ${ }^{48,63-65}$

\section{Genomics and biology of 45 tumours}

A limited number of studies have been performed to identify patterns of gene expression that are characteristic of stage $4 \mathrm{~S}$ neuroblastomas. Benard et al. ${ }^{46}$ studied 29 cases of metastatic neuroblastoma (12 of which were stage 4S) that lacked $M Y C N$ amplification. The investigators developed a genetic signature of 45 genes that was significantly associated with stage $4 \mathrm{~S}$ versus stage 4 tumours, and this was validated in an independent set of 22 tumours. Lavarino et al. ${ }^{66}$ conducted a similar study on 35 infants with metastatic neuroblastoma ( 25 had stage 4 disease and 10 had stage $4 \mathrm{~S}$ neuroblastoma). The tumours from patients with stage 4 disease were characterized by SCAs, whereas $90 \%$ of stage $4 \mathrm{~S}$ tumours were near-triploid with whole chromosome gains. ${ }^{66}$ The investigators found a differential expression of certain genes (such as CHD5, GNB1 and RERE) in stage 4 and stage $4 \mathrm{~S}$ neuroblastoma, with higher expression of genes mapping to the short arm of chromosome 1 in stage $4 \mathrm{~S}$ tumours, and to chromosome 11 for stage 4 tumours. A smaller proteomic study was performed on eight tumours from infants with stage 4 and 4 S, which identified another set of differentially expressed proteins across the two stages ${ }^{67}$ However, there was essentially no overlap of genes (or proteins) differentially expressed by regressing $4 \mathrm{~S}$ versus non-regressing infant tumours among these studies, suggesting that further investigation is needed.

\section{Metastatic and multifocal neuroblastic tumours}

The unique pattern of metastasis characteristic of stage $4 \mathrm{~S}$ disease might represent multifocal hyperplasia of neural crest precursors. ${ }^{68,69}$ Indeed, the tissues involved in the $4 \mathrm{~S}$ dissemination pattern are reminiscent of the tissue migration pattern of neural crest cells observed during development (Box 1). The concept of multifocal hyperplasia is based on the hypothesis that all cells have sustained a single initiating lesion, whereas true malignancies have sustained two or more critical mutations. ${ }^{68}$ In this regard, it is interesting that patients with constitutional activating mutations of $A L K$ and hereditary neuroblastoma do not present a $4 \mathrm{~S}$ pattern with increased frequency. ${ }^{20,24-26}$ To date, no biopsy or genotype analysis has been performed on multiple discrete nodules from patients with $4 \mathrm{~S}$ tumours to evaluate if those patients have identical or non-identical patterns of genomic changes. However, genomic analysis of primary $4 \mathrm{~S}$ tumours reveal clonal changes, consistent with a malignant process. ${ }^{47,66,70,71}$ Genomic analyses of multiple lesions in $4 \mathrm{~S}$ patients would likely address this issue definitively; however, considering the available data, we favour the hypothesis 
that stage $4 \mathrm{~S}$ tumour are metastatic dissemination of genetically identical cells, developing as biologically favourable disease in most cases.

\section{Box 1}

\section{Genes involved in neural crest development}

Insights into the mechanisms of neuroblastoma regression could potentially be gained by understanding the developmental biology of the neural crest, from which neuroblastomas are derived. During embryonic development, cells at the edge of the neural plate undergo epithelial-to-mesenchymal transition and migrate away from the neural tube. ${ }^{164}$ These cells follow different pathways, ultimately giving rise to a variety of tissues, including the enteric nervous system, melanocytes, dorsal root and sympathetic ganglia, and the chromaffin cells of the adrenal medulla. Numerous transcription factors and signalling molecules contribute to neural crest formation and to the differentiation of pluripotent neural crest cells. ${ }^{165}$ Furthermore, epigenetic control might also be important in determining cell fate. ${ }^{164}$ Much remains to be learned regarding genes normally involved in neural crest development and their role in neural crest-derived malignancies, such as neuroblastoma. However, expression profiling of a relatively small number of foetal adrenal neuroblasts, normal foetal adrenal cortical cells, and neuroblastoma tumours has suggested that there is differential expression of genes associated with earlier (ASCL1) versus later $(D L K l)$ time points in neural crest development in tumours classified as favourable versus unfavourable. ${ }^{166}$ Furthermore, MASH1, PHOX2B, Hand 2 BMP4 and other genes are known to have critical roles in chromaffin, dorsal root and sympathetic neural development. ${ }^{167,168}$ More recently, studies in zebrafish have confirmed that $P H O X 2 B$ is required for normal development of neural crest-derived cells that comprise the sympathetic ganglia, ${ }^{136}$ and that specific $P H O X 2 B$ aberrations can have varying effects on differentiation. ${ }^{169}$ Additional studies could potentially clarify if $P H O X 2 B$ and other genes involved in neural crest development have a role in neuroblastoma regression as well.

\section{Lessons from neuroblastoma screening}

The exact prevalence of spontaneous regression has been difficult to define precisely, but neuroblastoma mass-screening studies undertaken in Japan, Canada and Europe have provided useful information. The outcome of infants with neuroblastoma is substantially better than that of older children with this disease. Furthermore, almost all neuroblastomas produce catecholamines, and their metabolites-homovanillic acid (HVA) and vanillylmandelic acid (VMA) — can be readily detected in urine. ${ }^{72}$ Therefore, mass screening of infants for neuroblastoma by measuring urine VMA and HVA was initiated in Japan, ${ }^{11,12}$ with the goal of detecting tumours earlier and hopefully improving patient outcome. Initial results were promising, so similar efforts were initiated in North America and in Europe. ${ }^{13,14}$ Analysis of the data generated from these initiatives indicates that mass screening resulted in a substantial increase in the prevalence of neuroblastoma in the screened population ( 1:2,000 live births, versus 1:7,000 live births in unscreened populations), but overall mortality was unchanged. Importantly there was no significant 
decrease in the prevalence or mortality of neuroblastoma in patients older than 1 year. ${ }^{73-76}$ Thus, the goal to reduce neuroblastoma mortality by mass screening in infancy was not achieved, and screening efforts have essentially stopped worldwide.

Despite the fact the main objective of mass-screening was not reached, studies of this approach have provided valuable insights into the pathogenesis and clinical behaviour of biologically favourable tumours. The increased prevalence of neuroblastoma observed in the screened populations indicates that spontaneous regression of neuroblastoma (without clinical detection) occurs at least as frequently as neuroblastoma that is detected clinically. In addition, analyses performed on screened tumours showed that virtually all of them, regardless of their stage, were biologically favourable with respect to $M Y C N$ status and tumour cell ploidy, ${ }^{77-79}$ which is in contrast to the unfavourable biological features generally found in clinically detected tumours from older children. Importantly, these studies also indicated that biologically favourable tumours rarely evolve into biologically unfavourable tumours.

Although not intended as a neuroblastoma screening tool, there have been several reports of incidental prenatal detection of neuroblastoma by maternal ultrasound. ${ }^{80-82}$ These cases are similar, both clinically and biologically, to those identified by screening, and the vast majority of infants do well with little or no therapy. Infants under 1 year of age are at risk for both anaesthetic and surgical complications associated with resection of adrenal tumours, ${ }^{83}$ and so a strategy of expectant observation has been evaluated. Consistent with the findings from previous studies, ${ }^{84-86}$ a recent cooperative group trial demonstrated that more than $80 \%$ of such patients who had an adrenal mass detected in the perinatal period were spared surgical intervention, and the overall survival in this group was $100 \% .{ }^{87}$ Thus, careful observation is now considered standard care in young infants (up to 6 months of age) who have small tumours found incidentally.

\section{Mechanisms of spontaneous regression}

\section{Neurotrophin receptors and regression}

The Trk neurotrophin receptors-TrkA/NTRK1, TrkB/ NTRK2, and TrkC/NTRK3-have critical roles in the development and maintenance of the central and peripheral nervous systems. The cognate ligands for these receptors are nerve growth factor (NGF), brainderived neurotropic factor (BDNF) and neurotrophin-3 (NT3) growth factor, respectively. These receptors also have important roles in neuroblastoma pathogenesis. ${ }^{88-90}$ High TrkA expression levels are associated with favourable clinical and biological features, such as younger age, lower stage, and absence of $M Y C N$ amplification, and these patients have an excellent outcome. ${ }^{91-94}$ By contrast, TrkB is coexpressed at high levels with its ligand, $\mathrm{BDNF}$, in clinically and biologically unfavourable tumours, especially those with $M Y C N$ amplification. ${ }^{95}$ Activation of the TrkB-BDNF autocrine pathway can lead to invasion, metastasis, angiogenesis and drug resistance. ${ }^{95-99}$ The TrkA and TrkC receptors are also known as dependence receptors, as the absence of ligand activation will generate apoptotic signals. ${ }^{100,101}$ Coexpression of the P75/NGFR receptor can increase the sensitivity and specificity of all three Trk receptors for their cognate ligands; ${ }^{102,103}$ however, 
overexpression and activation of P75/NGFR in the absence of Trk expression can lead to apoptosis. ${ }^{101,104}$

Tumours from patients with low-stage and $4 \mathrm{~S}$ disease generally express high levels of TrkA. ${ }^{91-94}$ When cells derived from these tumours were put in primary culture in the presence of NGF, they underwent neuronal differentiation, and survived for months. By contrast, the same cells died via apoptosis within a week once deprived of NGF. ${ }^{93,105}$ Thus, these in vitro culture conditions seem to recapitulate the behaviour of TrkA-expressing neuroblastomas in patients whose tumours undergo neuronal differentiation or spontaneous regression (apoptosis), depending on the presence or absence of NGF in their microenvironment (Figure 2; Box 2).

\section{Box 2}

\section{Mechanisms of neuroblastoma differentiation}

Neuroblastic tumours consist of a histological spectrum that ranges from immature neuroblastoma and differentiating ganglioneuroblastoma, to ganglioneuroma. The extent of differentiation in the tumour has prognostic significance. ${ }^{19,161,170,171}$

Ganglioneuromas are comprised of individual ganglion cells or clusters surrounded by Schwannian stroma, but there is controversy concerning the origin of the Schwann cells in these tumours. Ambros et al. ${ }^{172}$ showed that the Schwann cells in ganglioneuromas had a normal DNA content, whereas the ganglionic cells were clonally aneuploid, suggesting the Schwann cells are normal, infiltrating host cells. Mora et al. ${ }^{142}$ showed that the stromal cells in treated neuroblastomas shared the same genomic abnormalities as immature neuronal components, suggesting they were part of the malignant process. Ambros and colleagues ${ }^{172}$ suggested that the Schwann cells were recruited into a less mature tumour by a Schwann-trophic factor, and the infiltrating Schwann cells in turn proliferated and produced NGF as well as other neurotrophins that caused an immature neuroblastoma to differentiate into a benign ganglioneuroma. ${ }^{173}$ Indeed, ganglioneuromas usually have abundant expression of TrkA, so they would be particularly prone to differentiate in the presence of NGF. Even immature neuroblastomas can undergo neuronal maturation into ganglionic cells in vitro in the presence of NGF. ${ }^{93,105}$ The identity of the Schwann-trophic factor (or factors) is unknown, and it is unclear why some tumours produce such factors, whereas others do not. However, ganglioneuromas are rare in infants, so this might represent a feature of favourable, TrkA-expressing tumours in older patients. Therapeutic approaches aimed at inducing differentiation in neuroblastomas have been suggested. Treatment with agents such as NGF might be effective at inducing differentiation in TrkA-expressing tumours. However, an alternative approach might be to induce expression of Schwann-trophic factors, resulting in tumour infiltration and differentiation via the neurotrophic factors produced by Schwann cells.

Abbreviations: NGF, nerve growth factor; TrkA, tropomyosin receptor kinase A.

Migrating neural crest precursors and favourable neuroblastomas that express TrkA on their cell surface survive (at least initially), despite a lack of available NGF, and the reason for 
this paradox is uncertain. One possible explanation comes from the identification of TrkAIII, a TrkA isoform that is expressed in normal sympathoadrenal progenitors as well as in some neuroblastomas. ${ }^{106,107}$ This isoform results from the alternative splicing of exons 6,7 and 9, which maintains the reading frame but abolishes the ligand-binding site, leading to constitutive activation of the kinase. Thus, the conversion from a TrkA-expressing, NGFdependent neuroblastoma to a NGF-independent one could be the consequence of a developmentally programmed isoform switch from TrkAIII to TrkAI. Alternatively, NGFindependent neuroblastomas could depend on another receptor or pathway for survival (such as TrkC or RET), ${ }^{108-110}$ and then switch dependence to TrkA, only to undergo apoptosis and regress in the absence of ligand. However, the available data regarding the possible mechanisms of neuroblastoma regression are most consistent with a TrkA dependence mechanism.

\section{Immunological mechanisms and regression}

Spontaneous regression of neuroblastomas and other types of cancer is sometimes associated with an acute infection. Regression of experimental tumour metastases can also be induced by immunomodulatory cytokines. ${ }^{111,112}$ Furthermore, tumour-infiltrating lymphocytes are observed occasionally in neuroblastomas, and there is evidence for the presence of both tumour-targeted T-cells and antineural antibodies in patients with neuroblastoma. ${ }^{113-115}$ Thus, a plausible theory is that spontaneous regression can be a consequence of a hostmediated immune response (Figure 2). Interestingly, the paraneoplastic opsomyoclonus syndrome (OMS) is associated with the presence of antineural antibodies and a favourable outcome in patients with neuroblastoma. ${ }^{113,116-118}$ About 50\% of patients with OMS have neuroblastoma, which suggests that the other $50 \%$ either had a neuroblastoma that regressed, or they have a de novo autoimmune disease. Unfortunately, the OMS can persist or recur long after removal and eradication of the tumour, so these patients might benefit from additional immunosuppressive therapy. ${ }^{119}$

Neuroblastoma cells from patients with high-risk disease have been shown to evade immune destruction by downregulating human leucocyte antigen (HLA) class I molecules. ${ }^{120}$ However, most tumours from patients with stage 4 S neuroblastoma express normal levels of HLA class I antigens. ${ }^{121}$ Upregulation of the expression of class I antigens in neuroblastoma cells can be induced in vitro by incubating cells with interferon- $\gamma$ (IFN- $\gamma) .{ }^{120}$ This raises the possibility that upregulation of HLA class I in vivo might represent a strategy to augment immune surveillance and ultimately promote tumour regression. However, although HLA class I upregulation following in vitro exposure to IFN- $\gamma$ has been shown to enhance the recognition of neuroblastoma cells by cytotoxic $\mathrm{T}$ cells, it could also reduce their susceptibility to killing by natural killer (NK) cells. ${ }^{120}$ Alteration in the expression of components of the antigen-processing machinery (including HLA class I heavy chain) have been demonstrated in primary tumours from patients with neuroblastoma, and may contribute to decreased killing of neuroblastoma cells. ${ }^{120}$ Further study of the role of these molecules in tumour regression is needed, as expression of these immune components has been studied in only a limited number of low stage and $4 \mathrm{~S}$ neuroblastomas. 
A study designed to assess the tumour-associated macrophage (TAM) infiltration in tumours from patients with various stages of $M Y C N$ non-amplified disease showed that INSS stage 4 tumours contained significantly increased numbers of CD163+ cells; however, this study reported that the number of TAM in INSS $4 \mathrm{~S}$ tumours is similar to locoregional neuroblastomas. ${ }^{126}$ Metastatic tumours from young patients ( $<18$ months old) had significantly higher expression levels of genes representing TAMs (CD33, CD16, IL6R, ILIO, FCGR3) than did tumours from patients $\geq 18$ months of age. This suggests that the inflammatory response and the tumour microenvironment might have important effects on the natural history and outcome of neuroblastoma in specific patient groups. ${ }^{126}$ This study was conducted on a small cohort, which likely limited the investigators' ability to evaluate expression of TAM-associated genes in patients with regressing tumours, and highlights the need for further study on the role of the immune system and the tumour microenvironment in the context of disease regression.

\section{Telomerase, telomeres and regression}

Telomeres are specialized structures at the ends of chromosomes that are involved in the replication and stability of the chromosome itself. They have an important role in guaranteeing genomic stability and are in a state of dynamic equilibrium. The regulation of the telomere length is controlled in part by the enzyme telomerase. Of note, telomerase expression is frequently high in cancer and immortalized cells, but low in most normal and senescent cells. ${ }^{127}$ Hiyama and colleagues ${ }^{128}$ studied the regulation of telomere length and the activity of the telomerase in 100 samples of neuroblastomas. Most of the tumours that exhibited a high level of telomerase activity were associated with a poor prognosis, and all tumours with $M Y C N$ amplification had high telomerase activity. Interestingly, most of the tumour samples from $4 \mathrm{~S}$ neuroblastoma had low telomerase activity or short telomeres, a pattern that is usually associated with senescent cells (Figure 2). ${ }^{128}$ Furthermore, Samy et al. ${ }^{129}$ transfected a neuroblastoma cell line (IGR-N-91) with a dominant negative form of human telomerase, h-Tert. The h-Tert-transfected neuroblastoma cells formed tumours that showed more apoptosis and reduced tumorigenicity in a mouse xenograft model compared to untransfected neuroblastoma cells.

These data suggest that loss of telomerase activity is a plausible mechanism to explain spontaneous regression of neuroblastoma, and possibly of other tumours. However, low telomerase activity is associated with biologically favourable tumours, which also have hyperdiploidy, high expression of TrkA and lack high-risk genomic features, such as $M Y C N$ amplification. ${ }^{130}$ Thus, the role of telomerase is not clear; the association between stage $4 \mathrm{~S}$ and regression might be related to the low telomerase activity or might depend on other favourable features associated with stage $4 \mathrm{~S}$, such as younger age, hyperdiploidy and lack of MYCN amplification. Nevertheless, high levels of telomerase activity is generally associated with a more-aggressive tumour behaviour and a poor prognosis in patients with neuroblastoma. ${ }^{131-133}$

\section{Epigenetic regulation and other mechanisms}

Changes in gene expression related to alterations in promoter methylation, histone modification or chromatin remodelling might also impact differentiation in neuroblastoma 
cells. Epigenetic changes affecting expression of genes relevant to neuroblastoma development were initially reported more than a decade ago, ${ }^{134,135}$ and several studies have suggested that alterations in gene methylation and histone modification are related to patient outcome (Figure 2). ${ }^{136-139}$ The correlation between epigenetic changes and neuroblastoma behaviour has been increasingly studied, particularly because next-generation sequencing analyses of neuroblastoma have reported a very limited number of previously unrecognized recurrent somatic mutations. ${ }^{41-44}$ Furthermore, data from other childhood tumour types, particularly Wilms tumour and medulloblastoma, suggest that epigenetic changes might help to explain poorly understood aspects of disease presentation and clinical behaviour. ${ }^{140-142}$

The development of genome-wide methylation detection methods has facilitated study of epigenetics in numerous tumour types, and in neuroblastomas specifically. ${ }^{139}$ Preliminary data showed that there are global differences in the methylomes of 22 neuroblastoma stage $4 \mathrm{~S}$ tumours compared to the methylomes of low-risk and high-risk tumours and to the methylome of normal brain tissues. ${ }^{47}$ In the $4 \mathrm{~S}$ samples, reduced promoter methylation was observed in $97 \%$ of the genes in which differential methylation was detected. Specifically, differentially methylated promoters were enriched for genes known to have binding sites for transcription factors involved in cell differentiation (such as LEF1, TCF3, ETS2, and PITX2). ${ }^{47}$ Other investigators have also reported different patterns of methylation in tumours from patients with $4 \mathrm{~S}$ versus other disease stages, ${ }^{139}$ but additional studies are needed to confirm and extend these initial findings. Studies of agents that affect DNA methylation status, histone modification, or chromatin modifiers during differentiation and regression are ongoing, ${ }^{143-145}$ but currently there are no clinical trials of epigenetic modifiers in stage $4 \mathrm{~S}$ neuroblastomas.

\section{Therapeutic implications of regression}

\section{Targeting the TrkA pathway}

One of the most promising approaches for the induction of apoptosis and tumour regression in neuroblastomas is targeting the TrkA neurotrophin receptor pathway. This is based on the observation that TrkA-expressing tumour cells placed in culture will survive and even differentiate in the presence of NGF, but undergo apoptosis in its absence. ${ }^{105}$ Thus, depriving cells of NGF or inhibiting TrkA signalling might be an effective approach to induce regression. Lestaurtinib (CEP-701) is a small molecule that targets Trk neurotrophin receptors (TrkA, TrkB and TrkC), and it has shown preclinical activity against TrkBexpressing neuroblastoma xenografts. ${ }^{146-149}$ Furthermore, lestaurtinib, when given at biologically effective doses, has shown significant clinical activity in a phase I trial in children with recurrent and/or refractory neuroblastoma. ${ }^{150}$ Lestaurtinib is not being supported for future clinical trials, but these studies provide proof-of-principle that Trkselective inhibitors could be effective in the treatment of neuroblastomas driven by Trk receptors. Indeed, several second-generation Trk inhibitors are currently in phase I clinical trials or in preclinical development. ${ }^{151-154}$ These agents are potent inhibitors of all three Trk family neurotrophin receptors, so the same agent could be used to target TrkA in favourable $4 \mathrm{~S}$ tumours, and TrkB in unfavourable tumours. 
In general, new agents are tested in patients with recurrent and/or refractory disease; therefore, new Trk inhibitors will not be tested initially in infants with de novo stage $4 \mathrm{~S}$ disease or other patients with locoregional tumours and biologically favourable features. However, there is significant mortality due to respiratory compromise among very young infants with stage $4 \mathrm{~S}$ neuroblastoma and hepatomegaly. ${ }^{155,156}$ If second-generation Trk inhibitors prove to be safe and effective against TrkB-expressing, high-risk disease, it would be reasonable to consider administration of these agents in patients with TrkA-expressing $4 \mathrm{~S}$ neuroblastoma and massive liver involvement in lieu of chemotherapy or radiation therapy. Theoretically, a Trk inhibitor could initiate the process of apoptosis and regression in these tumours. It would be highly desirable to have an agent, such as a Trk inhibitor, that can induce regression directly, rather than waiting for it to occur spontaneously. Trk inhibitor therapy might also be used for infants with large abdominal tumours or 'dumbbell tumours' with intraspinal extension, to spare such patients the toxicity and long-term side effects of laminectomy, chemotherapy or spinal radiation.

\section{Immunological approaches}

Immunotherapy using a chimeric antibody (ch14.18) directed against the disialoganglioside GD2 has been incorporated into frontline treatment of patients with high-risk neuroblastoma, ${ }^{157}$ and very preliminary studies have been performed using adoptive immunotherapy in patients with relapsed and refractory disease. ${ }^{158}$ Additional studies of the immunology of differentiation and regression are expected to influence the evolution of current immunotherapeutic approaches and could potentially result in new strategies to accelerate regression in young infants with acute life-threatening, but biologically favourable disease. Immune modulation to induce regression could potentially be advantageous for patients with $4 \mathrm{~S}$ or locoregional disease, and a trend in the field has been to reduce conventional cytotoxic therapy and avoid aggressive surgery in patients with favourable prognoses. ${ }^{84,87,159}$ The toxicities associated with currently available immunocytokine therapies are considerable, and little is known regarding late effects of these therapies, especially in very young infants. Less toxic immune modulation therapy could be considered, including therapy designed to enhance immune surveillance by increasing HLA I expression on neuroblastoma cells. However, as noted above, strategies to enhance one component of the immune system may diminish the antitumour effects of another key component. There is an increasing need for a better understanding of the complex interactions between neuroblastoma cells and the immune system, and of the multiple implications of immune modulation in very young children.

\section{Other approaches}

At the present time, there are no therapeutic approaches available to influence telomere length in neuroblastomas. However, in addition to targeted inhibition of the TrkA pathway or immunological therapy, there are other approaches that might be considered for these patients, For example, the retinoids are a class of compounds that have been shown to induce cellular differentiation and decrease proliferation of neuroblastoma cells in vitro, presumably mediated by the induction of expression of neural differentiation genes. ${ }^{160}$ Indeed, the retinoid isotretinoin (13-cisretinoic acid) has been incorporated into frontline therapy for children with high-risk neuroblastoma in an effort to induce differentiation in 
vivo in states of minimal residual disease following intensive, multimodality therapy. ${ }^{161}$ The precise mechanisms by which isotretinoin induces differentiation are unclear, but it seems that retinoids are associated with increased expression of Trk receptors. ${ }^{160}$

Vorinostat, a histone deacetylase inhibitor, has been administered in combination with isotretinoin in children with relapsed or refractory disease in an effort to further induce neuroblastoma cell differentiation. A patient with neuroblastoma who had evaluable disease experienced a complete response to therapy on one phase I trial, ${ }^{162}$ although no objective responses were seen in a second study. ${ }^{163}$ Further studies of epigenetic changes in neuroblastoma cells that undergo differentiation versus those that do not differentiate could lead to the development of more specific and effective agents that can alter gene expression in neuroblastomas and consequently induce tumour regression.

\section{Conclusions}

Neuroblastomas show a remarkable capacity to undergo spontaneous regression. The prevalence of this phenomenon is hard to determine precisely, but the experience from mass-screening programmes suggests that there are at least as many children who have tumours undergoing spontaneous regression without detection as there are patients with neuroblastoma detected clinically. Further exploration of this issue and a greater understanding of the normal mechanism(s) of spontaneous regression might allow the identification of tumours that have the capacity to undergo spontaneous regression and to induce regression in susceptible tumours using pharmacological, biological or immunological approaches. However, to this end, we will need to study samples from a substantial number of regressing tumours, or perhaps establish an animal model that suitably mimics the process of spontaneous regression. At the present time, the most promising therapeutic approach would be aimed at inhibiting the TrkA receptor pathway. However, most Trk inhibitors are potent inhibitors of TrkA, TrkB and TrkC. Before these agents are used to treat infants with stage $4 \mathrm{~S}$ disease, clinical trials of second- generation Trk inhibitors would need to demonstrate safety and efficacy against TrkB-expressing recurrent and/or refractory neuroblastomas.

\section{Acknowledgments}

This work was supported in part by NIH grants R01-CA094194 and R01-039,771; Alex's Lemonade Stand Foundation; and the Audrey E. Evans endowed chair (G.M.B.).

\section{References}

1. Brodeur, GM.; Maris, JM. Principles and Practice of Pediatric Oncology. Pizzo, PA.; Poplack, DG., editors. Lippincott, Williams and Wilkins; Philadelphia: 2010. p. 786-822.

2. Maris JM, Hogarty MD, Bagatell R, Cohn SL. Neuroblastoma. Lancet. 2007; 369:2106-2120. [PubMed: 17586306]

3. Smith MA, et al. Outcomes for children and adolescents with cancer: challenges for the twenty-first century. J Clin Oncol. 2010; 28:2625-2634. [PubMed: 20404250]

4. Gatta G, et al. Childhood cancer survival in Europe 1999-2007: results of EUROCARE-5 - a population-based study. Lancet Oncol. 2014; 15:35-47. [PubMed: 24314616] 
5. Kreissman SG, et al. Purged versus non-purged peripheral blood stem-cell transplantation for highrisk neuroblastoma (COG A3973): a randomised phase 3 trial. Lancet Oncol. 2013; 14:999-1008. [PubMed: 23890779]

6. Diede SJ. Spontaneous regression of metastatic cancer: learning from neuroblastoma. Nat Rev Cancer. 2014; 14:71-72. [PubMed: 24616911]

7. Matthay KK. Stage 4S neuroblastoma: what makes it special? J Clin Oncol. 1998; 16:2003-2006. [PubMed: 9626196]

8. Nakagawara A. Molecular basis of spontaneous regression of neuroblastoma: role of neurotrophic signals and genetic abnormalities. Hum Cell. 1998; 11:115-124. [PubMed: 10086274]

9. Nickerson HJ, et al. Favorable biology and outcome of stage IV-S neuroblastoma with supportive care or minimal therapy: a Children's Cancer Group study. J Clin Oncol. 2000; 18:477-486. [PubMed: 10653863]

10. Pritchard J, Hickman JA. Why does stage 4s neuroblastoma regress spontaneously? Lancet. 1994; 344:869-870. [PubMed: 7916408]

11. Yamamoto K, et al. Marginal decrease in mortality and marked increase in incidence as a result of neuroblastoma screening at 6 months of age: cohort study in seven prefectures in Japan. J Clin Oncol. 2002; 20:1209-1214. [PubMed: 11870162]

12. Sawada T, et al. Mass screening for neuroblastoma in Japan. Pediatr Hematol Oncol. 1991; 8:93109. [PubMed: 1863547]

13. Erttmann R, et al. 10 years' neuroblastoma screening in Europe: preliminary results of a clinical and biological review from the Study Group for Evaluation of Neuroblastoma Screening in Europe (SENSE). Eur J Cancer. 1998; 34:1391-1397. [PubMed: 9849422]

14. Woods WG, et al. A population-based study of the usefulness of screening for neuroblastoma. Lancet. 1996; 348:1682-1687. [PubMed: 8973429]

15. Brodeur GM. Neuroblastoma: biological insights into a clinical enigma. Nat Rev Cancer. 2003; 3:203-216. [PubMed: 12612655]

16. Hoehner JC, Olsen L, Sandstedt B, Kaplan DR, Pahlman S. Association of neurotrophin receptor expression and differentiation in human neuroblastoma. Am J Pathol. 1995; 147:102-113. [PubMed: 7604872]

17. Haas D, Ablin AR, Miller C, Zoger S, Matthay KK. Complete pathologic maturation and regression of stage IVS neuroblastoma without treatment. Cancer. 1988; 62:818-825. [PubMed: 3293764]

18. Garvin JH Jr, Lack EE, Berenberg W, Frantz CN. Ganglioneuroma presenting with differentiated skeletal metastases Report of a case. Cancer. 1984; 54:357-360. [PubMed: 6722750]

19. Shimada H, et al. Terminology and morphologic criteria of neuroblastic tumors: recommendations by the International Neuroblastoma Pathology Committee. Cancer. 1999; 86:349-363. [PubMed: 10421272]

20. Mosse YP, et al. Identification of ALK as a major familial neuroblastoma predisposition gene. Nature. 2008; 455:930-935. [PubMed: 18724359]

21. Shojaei-Brosseau T, et al. Genetic epidemiology of neuroblastoma: a study of 426 cases at the Institut Gustave-Roussy in France. Pediatr Blood Cancer. 2004; 42:99-105. [PubMed: 14752801]

22. Mosse YP, et al. Germline PHOX2B mutation in hereditary neuroblastoma. Am J Hum Genet. 2004; 75:727-730. [PubMed: 15338462]

23. Maris JM, et al. Evidence for a hereditary neuroblastoma predisposition locus at chromosome 16p12-13. Cancer Res. 2002; 62:6651-6658. [PubMed: 12438263]

24. Chen Y, et al. Oncogenic mutations of ALK kinase in neuroblastoma. Nature. 2008; 455:971-974. [PubMed: 18923524]

25. George RE, et al. Activating mutations in ALK provide a therapeutic target in neuroblastoma. Nature. 2008; 455:975-978. [PubMed: 18923525]

26. Janoueix-Lerosey I, et al. Somatic and germline activating mutations of the ALK kinase receptor in neuroblastoma. Nature. 2008; 455:967-970. [PubMed: 18923523]

27. Raabe EH, et al. Prevalence and functional consequence of PHOX2B mutations in neuroblastoma. Oncogene. 2008; 27:469-476. [PubMed: 17637745] 
28. Trochet D, et al. Germline mutations of the paired-like homeoBox 2B (PHOX2B) gene in neuroblastoma. Am J Hum Genet. 2004; 74:761-764. [PubMed: 15024693]

29. Bosse KR, et al. Common variation at BARD1 results in the expression of an oncogenic isoform that influences neuroblastoma susceptibility and oncogenicity. Cancer Res. 2012; 72:2068-2078. [PubMed: 22350409]

30. Capasso M, et al. Common variations in BARD1 influence susceptibility to high-risk neuroblastoma. Nat Genet. 2009; 41:718-723. [PubMed: 19412175]

31. Diskin SJ, et al. Common variation at $6 \mathrm{q} 16$ within HACE1 and LIN28B influences susceptibility to neuroblastoma. Nat Genet. 2012; 44:1126-1130. [PubMed: 22941191]

32. Nguyen le B, et al. Phenotype restricted genome-wide association study using a genecentric approach identifies three low-risk neuroblastoma susceptibility Loci. PLoS Genet. 2011; 7:e1002026. [PubMed: 21436895]

33. Wang K, et al. Integrative genomics identifies LMO1 as a neuroblastoma oncogene. Nature. 2011; 469:216-220. [PubMed: 21124317]

34. Weiss WA, Aldape K, Mohapatra G, Feuerstein BG, Bishop JM. Targeted expression of MYCN causes neuroblastoma in transgenic mice. EMBO J. 1997; 16:2985-2995. [PubMed: 9214616]

35. Chen Z, et al. Mdm2 deficiency suppresses MYCN-driven neuroblastoma tumorigenesis in vivo. Neoplasia. 2009; 11:753-762. [PubMed: 19649205]

36. Berry T, et al. The ALK(F1174L) mutation potentiates the oncogenic activity of MYCN in neuroblastoma. Cancer Cell. 2012; 22:117-130. [PubMed: 22789543]

37. Heukamp LC, et al. Targeted expression of mutated ALK induces neuroblastoma in transgenic mice. Sci Transl Med. 2012; 4:141ra91.

38. Molenaar JJ, et al. LIN28B induces neuroblastoma and enhances MYCN levels via let-7 suppression. Nat Genet. 2012; 44:1199-1206. [PubMed: 23042116]

39. Mosse YP, et al. Neuroblastomas have distinct genomic DNA profiles that predict clinical phenotype and regional gene expression. Genes Chromosomes Cancer. 2007; 46:936-949. [PubMed: 17647283]

40. Schleiermacher G, et al. Segmental chromosomal alterations have prognostic impact in neuroblastoma: a report from the INRG project. Br J Cancer. 2012; 107:1418-1422. [PubMed: 22976801]

41. Pugh TJ, et al. The genetic landscape of high-risk neuroblastoma. Nat Genet. 2013; 45:279-284. [PubMed: 23334666]

42. Cheung NK, et al. Association of age at diagnosis and genetic mutations in patients with neuroblastoma. JAMA. 2012; 307:1062-1071. [PubMed: 22416102]

43. Sausen M, et al. Integrated genomic analyses identify ARID1A and ARID1B alterations in the childhood cancer neuroblastoma. Nat Genet. 2013; 45:12-17. [PubMed: 23202128]

44. Molenaar JJ, et al. Sequencing of neuroblastoma identifies chromothripsis and defects in neuritogenesis genes. Nature. 2012; 483:589-593. [PubMed: 22367537]

45. Santo EE, et al. Oncogenic activation of FOXR1 by 11q23 intrachromosomal deletion-fusions in neuroblastoma. Oncogene. 2012; 31:1571-1581. [PubMed: 21860421]

46. Benard J, et al. MYCN-non-amplified metastatic neuroblastoma with good prognosis and spontaneous regression: a molecular portrait of stage 4S. Mol Oncol. 2008; 2:261-271. [PubMed: 19383347]

47. Diskin, SJ., et al. Advances in Neuroblastoma Research. Cologne; 2014. Integrative genomic and epigenomic characterization of stage 4 S neuroblastoma gene expression [abstract]; p. POB083

48. Taggart DR, et al. Prognostic value of the stage 4S metastatic pattern and tumor biology in patients with metastatic neuroblastoma diagnosed between birth and 18 months of age. J Clin Oncol. 2011; 29:4358-4364. [PubMed: 21969516]

49. Challis GB, Stam HJ. The spontaneous regression of cancer. A review of cases from 1900 to 1987. Acta Oncol. 1990; 29:545-550. [PubMed: 2206563]

50. Everson TC. Spontaneous regression of cancer. Ann N Y Acad Sci. 1964; 114:721-735.

51. Everson, TC.; Cole, WH. Spontaneous regression of cancer. W. B. Saunders \& Co; Philadelphia: 1966.

Nat Rev Clin Oncol. Author manuscript; available in PMC 2014 December 01. 
52. Papac RJ. Spontaneous regression of cancer: possible mechanisms. In Vivo. 1998; 12:571-578. [PubMed: 9891219]

53. Beckwith JB, Perrin EV. In situ neuroblastomas: a contribution to the natural history of neural crest tumors. Am J Pathol. 1963; 43:1089-1104. [PubMed: 14099453]

54. Ikeda Y, Lister J, Bouton JM, Buyukpamukcu M. Congenital neuroblastoma, neuroblastoma in situ, and the normal fetal development of the adrenal. J Pediatr Surg. 1981; 16:636-644. [PubMed: 7277167]

55. Turkel SB, Itabashi HH. The natural history of neuroblastic cells in the fetal adrenal gland. Am J Pathol. 1974; 76:225-244. [PubMed: 4843383]

56. D'Angio GJ, Evans AE, Koop CE. Special pattern of widespread neuroblastoma with a favourable prognosis. Lancet. 1971; 1:1046-1049. [PubMed: 4102970]

57. Evans AE, D’Angio GJ, Randolph J. A proposed staging for children with neuroblastoma. Children's cancer study group A. Cancer. 1971; 27:374-378. [PubMed: 5100400]

58. George RE, et al. High-risk neuroblastoma treated with tandem autologous peripheral-blood stem cell-supported transplantation: long-term survival update. J Clin Oncol. 2006; 24:2891-2896. [PubMed: 16782928]

59. Matthay KK, et al. Treatment of high-risk neuroblastoma with intensive chemotherapy, radiotherapy, autologous bone marrow transplantation, and 13-cis-retinoic acid. Children's Cancer Group. N Engl J Med. 1999; 341:1165-1173. [PubMed: 10519894]

60. Brodeur GM, et al. Revisions of the international criteria for neuroblastoma diagnosis, staging, and response to treatment. J Clin Oncol. 1993; 11:1466-1477. [PubMed: 8336186]

61. Brodeur GM, et al. International criteria for diagnosis, staging, and response to treatment in patients with neuroblastoma. J Clin Oncol. 1988; 6:1874-1881. [PubMed: 3199170]

62. Monclair T, et al. The International Neuroblastoma Risk Group (INRG) staging system: an INRG Task Force report. J Clin Oncol. 2009; 27:298-303. [PubMed: 19047290]

63. Cozzi DA, et al. Long-term follow-up of the "wait and see" approach to localized perinatal adrenal neuroblastoma. World J Surg. 2013; 37:459-465. [PubMed: 23135423]

64. Fisher JP, Tweddle DA. Neonatal neuroblastoma. Semin Fetal Neonatal Med. 2012; 17:207-215. [PubMed: 22673527]

65. Kushner BH, et al. Survival from locally invasive or widespread neuroblastoma without cytotoxic therapy. J Clin Oncol. 1996; 14:373-381. [PubMed: 8636746]

66. Lavarino C, et al. Specific gene expression profiles and chromosomal abnormalities are associated with infant disseminated neuroblastoma. BMC Cancer. 2009; 9:44. [PubMed: 19192278]

67. Yu F, et al. Proteomics-based identification of spontaneous regression-associated proteins in neuroblastoma. J Pediatr Surg. 2011; 46:1948-1955. [PubMed: 22008333]

68. Knudson AG Jr, Meadows AT. Regression of neuroblastoma IV-S: a genetic hypothesis. N Engl J Med. 1980; 302:1254-1256. [PubMed: 6767985]

69. van Noesel MM. Neuroblastoma stage 4S: a multifocal stem-cell disease of the developing neural crest. Lancet Oncol. 2012; 13:229-230. [PubMed: 22381931]

70. Spitz R, et al. Favorable outcome of triploid neuroblastomas: a contribution to the special oncogenesis of neuroblastoma. Cancer Genet Cytogenet. 2006; 167:51-56. [PubMed: 16682287]

71. Ambros PF, et al. Regression and progression in neuroblastoma. Does genetics predict tumour behaviour? Eur J Cancer. 1995; 31A:510-515. [PubMed: 7576955]

72. LaBrosse EH, Comoy E, Bohuon C, Zucker JM, Schweisguth O. Catecholamine metabolism in neuroblastoma. J Natl Cancer Inst. 1976; 57:633-638. [PubMed: 10450]

73. Bessho F. Comparison of the incidences of neuroblastoma for screened and unscreened cohorts. Acta Paediatr. 1999; 88:404-406. [PubMed: 10342538]

74. Schilling FH, et al. Neuroblastoma screening at one year of age. N Engl J Med. 2002; 346:10471053. [PubMed: 11932471]

75. Woods WG, et al. Screening of infants and mortality due to neuroblastoma. N Engl J Med. 2002; 346:1041-1046. [PubMed: 11932470] 
76. Yamamoto K, et al. Marginal decrease in mortality and marked increase in incidence as a result of neuroblastoma screening at 6 months of age: cohort study in seven prefectures in Japan. J Clin Oncol. 2002; 20:1209-1214. [PubMed: 11870162]

77. Brodeur GM, Ambros PF, Favrot MC. Biological aspects of neuroblastoma screening. Med Ped Oncol. 1998; 31:394-400.

78. Hayashi Y, Hanada R, Yamamoto K. Biology of neuroblastomas in Japan found by screening. Am J Pediatr Hematol Oncol. 1992; 14:342-347. [PubMed: 1456401]

79. Kaneko Y, et al. Current urinary mass screening for catecholamine metabolites at 6 months of age may be detecting only a small portion of high-risk neuroblastomas: A chromosome and N-myc amplification study. J Clin Oncol. 1990; 8:2005-2013. [PubMed: 2230892]

80. Acharya S, et al. Prenatally diagnosed neuroblastoma. Cancer. 1997; 80:304-310. [PubMed: 9217044]

81. Ho PT, et al. Prenatal detection of neuroblastoma: a ten-year experience from the Dana-Farber Cancer Institute and Children's Hospital. Pediatrics. 1993; 92:358-364. [PubMed: 8361790]

82. Saylors RL 3rd, Cohn SL, Morgan ER, Brodeur GM. Prenatal detection of neuroblastoma by fetal ultrasonography. Am J Pediatr Hematol Oncol. 1994; 16:356-360. [PubMed: 7978056]

83. Ikeda H, et al. Surgical treatment of neuroblastomas in infants under 12 months of age. J Pediatr Surg. 1998; 33:1246-1250. [PubMed: 9721996]

84. Hero B, et al. Localized infant neuroblastomas often show spontaneous regression: results of the prospective trials NB95-S and NB97. J Clin Oncol. 2008; 26:1504-1510. [PubMed: 18349403]

85. Oue T, et al. Profile of neuroblastoma detected by mass screening, resected after observation without treatment: results of the Wait and See pilot study. J Pediatr Surg. 2005; 40:359-363. [PubMed: 15750929]

86. Nishihira H, et al. Natural course of neuroblastoma detected by mass screening: a 5-year prospective study at a single institution. J Clin Oncol. 2000; 18:3012-3017. [PubMed: 10944135]

87. Nuchtern JG, et al. A prospective study of expectant observation as primary therapy for neuroblastoma in young infants: a Children's Oncology Group study. Ann Surg. 2012; 256:573580. [PubMed: 22964741]

88. Brodeur GM, et al. Trk receptor expression and inhibition in neuroblastomas. Clin Cancer Res. 2009; 15:3244-3250. [PubMed: 19417027]

89. Brodeur GM, et al. Expression of TrkA, TrkB and TrkC in human neuroblastomas. J Neurooncol. 1997; 31:49-55. [PubMed: 9049830]

90. Thiele CJ, Li Z, McKee AE. On Trk-the TrkB signal transduction pathway is an increasingly important target in cancer biology. Clin Cancer Res. 2009; 15:5962-5967. [PubMed: 19755385]

91. Kogner P, et al. Coexpression of messenger RNA for TRK protooncogene and low affinity nerve growth factor receptor in neuroblastoma with favorable prognosis. Cancer Res. 1993; 53:20442050. [PubMed: 8481906]

92. Nakagawara A, Arima M, Azar CG, Scavarda NJ, Brodeur GM. Inverse relationship between trk expression and N-myc amplification in human neuroblastomas. Cancer Res. 1992; 52:1364-1368. [PubMed: 1737399]

93. Nakagawara A, et al. Association between high levels of expression of the TRK gene and favorable outcome in human neuroblastoma. N Engl J Med. 1993; 328:847-854. [PubMed: 8441429]

94. Stram D, Seeger RC. Lack of high-affinity nerve growth factor receptors in aggressive neuroblastomas. J Natl Cancer Inst. 1993; 85:377-384. [PubMed: 8433391]

95. Nakagawara A, Azar CG, Scavarda NJ, Brodeur GM. Expression and function of TRK-B and BDNF in human neuroblastomas. Mol Cell Biol. 1994; 14:759-767. [PubMed: 8264643]

96. Acheson A, et al. A BDNF autocrine loop in adult sensory neurons prevents cell death. Nature. 1995; 374:450-453. [PubMed: 7700353]

97. Jaboin J, Kim CJ, Kaplan DR, Thiele CJ. Brain-derived neurotrophic factor activation of TrkB protects neuroblastoma cells from chemotherapy-induced apoptosis via phosphatidylinositol $3^{\prime}$ kinase pathway. Cancer Res. 2002; 62:6756-6763. [PubMed: 12438277] 
98. Matsumoto K, Wada RK, Yamashiro JM, Kaplan DR, Thiele CJ. Expression of brain-derived neurotrophic factor and p145TrkB affects survival, differentiation, and invasiveness of human neuroblastoma cells. Cancer Res. 1995; 55:1798-1806. [PubMed: 7712490]

99. Nakamura K, et al. Brain-derived neurotrophic factor activation of TrkB induces vascular endothelial growth factor expression via hypoxia-inducible factor-1alpha in neuroblastoma cells. Cancer Res. 2006; 66:4249-4255. [PubMed: 16618748]

100. Goldschneider D, Mehlen P. Dependence receptors: a new paradigm in cell signaling and cancer therapy. Oncogene. 2010; 29:1865-1882. [PubMed: 20173780]

101. Rabizadeh S, Ye X, Wang JJ, Bredesen DE. Neurotrophin dependence mediated by p75NTR: contrast between rescue by BDNF and NGF. Cell Death Differ. 1999; 6:1222-1227. [PubMed: 10637439]

102. Hantzopoulos PA, Suri C, Glass DJ, Goldfarb MP, Yancopoulos GD. The low affinity NGF receptor, p75, can collaborate with each of the Trks to potentiate functional responses to the neurotrophins. Neuron. 1994; 13:187-201. [PubMed: 8043276]

103. Ho R, et al. The effect of P75 on Trk receptors in neuroblastomas. Cancer Lett. 2011; 305:76-85. [PubMed: 21419569]

104. Bamji SX, et al. The p75 neurotrophin receptor mediates neuronal apoptosis and is essential for naturally occurring sympathetic neuron death. J Cell Biol. 1998; 140:911-923. [PubMed: 9472042]

105. Nakagawara A, Brodeur GM. Role of neurotrophins and their receptors in human neuroblastomas: a primary culture study. Eur J Cancer. 1997; 33:2050-2053. [PubMed: 9516851]

106. Tacconelli A, et al. TrkA alternative splicing: a regulated tumor-promoting switch in human neuroblastoma. Cancer Cell. 2004; 6:347-360. [PubMed: 15488758]

107. Tacconelli A, Farina AR, Cappabianca L, Gulino A, Mackay AR. Alternative TrkAIII splicing: a potential regulated tumor-promoting switch and therapeutic target in neuroblastoma. Future Oncol. 2005; 1:689-698. [PubMed: 16556046]

108. Kahane N, Kalcheim C. Expression of trkC receptor mRNA during development of the avian nervous system. J Neurobiol. 1994; 25:571-584. [PubMed: 8071661]

109. Pachnis V, Mankoo B, Costantini F. Expression of the c-ret proto-oncogene during mouse embryogenesis. Development. 1993; 119:1005-1017. [PubMed: 8306871]

110. Tsuzuki T, et al. Spatial and temporal expression of the ret proto-oncogene product in embryonic, infant and adult rat tissues. Oncogene. 1995; 10:191-198. [PubMed: 7824273]

111. Salcedo R, et al. Immunologic and therapeutic synergy of IL-27 and IL-2: enhancement of T cell sensitization, tumor-specific CTL reactivity and complete regression of disseminated neuroblastoma metastases in the liver and bone marrow. J Immunol. 2009; 182:4328-4338. [PubMed: 19299733]

112. Salcedo R, et al. IL-27 mediates complete regression of orthotopic primary and metastatic murine neuroblastoma tumors: role for CD8+ T cells. J Immunol. 2004; 173:7170-7182. [PubMed: 15585838]

113. Antunes NL, et al. Antineuronal antibodies in patients with neuroblastoma and paraneoplastic opsoclonus-myoclonus. J Pediatr Hematol Oncol. 2000; 22:315-320. [PubMed: 10959901]

114. Kataoka Y, Matsumura T, Yamamoto S, Sugimoto T, Sawada T. Distinct cytotoxicity against neuroblastoma cells of peripheral blood and tumor-infiltrating lymphocytes from patients with neuroblastoma. Cancer Lett. 1993; 73:11-21. [PubMed: 8402593]

115. Valteau D, et al. T-cell receptor repertoire in neuroblastoma patients. Cancer Res. 1996; 56:362369. [PubMed: 8542593]

116. Cooper R, et al. Opsoclonus-myoclonus-ataxia syndrome in neuroblastoma: histopathologic features-a report from the Children's Cancer Group. Med Pediatr Oncol. 2001; 36:623-629. [PubMed: 11344493]

117. Pranzatelli MR, et al. B- and T-cell markers in opsoclonus-myoclonus syndrome: immunophenotyping of CSF lymphocytes. Neurology. 2004; 62:1526-1532. [PubMed: 15136676] 
118. Rudnick E, et al. Opsoclonus-myoclonus-ataxia syndrome in neuroblastoma: clinical outcome and antineuronal antibodies-a report from the Children's Cancer Group Study. Med Pediatr Oncol. 2001; 36:612-622. [PubMed: 11344492]

119. Russo C, Cohn SL, Petruzzi MJ, de Alarcon PA. Long-term neurologic outcome in children with opsoclonus-myoclonus associated with neuroblastoma: a report from the Pediatric Oncology Group. Med Pediatr Oncol. 1997; 28:284-288. [PubMed: 9078325]

120. Raffaghello L, et al. Multiple defects of the antigen-processing machinery components in human neuroblastoma: immunotherapeutic implications. Oncogene. 2005; 24:4634-4644. [PubMed: 15897905]

121. Squire R, Fowler CL, Brooks SP, Rich GA, Cooney DR. The relationship of class I MHC antigen expression to stage IV-S disease and survival in neuroblastoma. J Pediatr Surg. 1990; 25:381386. [PubMed: 2329454]

122. Bin Q, Johnson BD, Schauer DW, Casper JT, Orentas RJ. Production of macrophage migration inhibitory factor by human and murine neuroblastoma. Tumour Biol. 2002; 23:123-129. [PubMed: 12218292]

123. Castriconi R, et al. Natural killer cell-mediated killing of freshly isolated neuroblastoma cells: critical role of DNAX accessory molecule-1-poliovirus receptor interaction. Cancer Res. 2004; 64:9180-9184. [PubMed: 15604290]

124. Raffaghello L, et al. Downregulation and/or release of NKG2D ligands as immune evasion strategy of human neuroblastoma. Neoplasia. 2004; 6:558-568. [PubMed: 15548365]

125. Ren $\mathrm{Y}$, et al. Inhibition of tumor growth and metastasis in vitro and in vivo by targeting macrophage migration inhibitory factor in human neuroblastoma. Oncogene. 2006; 25:35013508. [PubMed: 16449971]

126. Asgharzadeh $\mathrm{S}$, et al. Clinical significance of tumor-associated inflammatory cells in metastatic neuroblastoma. J Clin Oncol. 2012; 30:3525-3532. [PubMed: 22927533]

127. Kim NW, et al. Specific association of human telomerase activity with immortal cells and cancer. Science. 1994; 266:2011-2015. [PubMed: 7605428]

128. Hiyama E, et al. Correlating telomerase activity levels with human neuroblastoma outcomes. Nat Med. 1995; 1:249-255. [PubMed: 7585042]

129. Samy M, et al. Loss of the malignant phenotype of human neuroblastoma cells by a catalytically inactive dominant-negative hTERT mutant. Mol Cancer Ther. 2012; 11:2384-2393. [PubMed: 22933702]

130. Brodeur GM. Do the ends justify the means? Nat Med. 1995; 1:203-205. [PubMed: 7585030]

131. Krams M, et al. Full-length telomerase reverse transcriptase messenger RNA is an independent prognostic factor in neuroblastoma. Am J Pathol. 2003; 162:1019-1026. [PubMed: 12598334]

132. Ohali A, et al. Telomere length is a prognostic factor in neuroblastoma. Cancer. 2006; 107:13911399. [PubMed: 16917952]

133. Streutker CJ, Thorner P, Fabricius N, Weitzman S, Zielenska M. Telomerase activity as a prognostic factor in neuroblastomas. Pediatr Dev Pathol. 2001; 4:62-67. [PubMed: 11200492]

134. Astuti D, et al. RASSF1A promoter region CpG island hypermethylation in phaeochromocytomas and neuroblastoma tumours. Oncogene. 2001; 20:7573-7577. [PubMed: 11709729]

135. Takita $J$, et al. Absent or reduced expression of the caspase 8 gene occurs frequently in neuroblastoma, but not commonly in Ewing sarcoma or rhabdomyosarcoma. Med Pediatr Oncol. 2000; 35:541-543. [PubMed: 11107112]

136. Barbieri E, et al. Histone chaperone CHAF1A inhibits differentiation and promotes aggressive neuroblastoma. Cancer Res. 2014; 74:765-774. [PubMed: 24335960]

137. Grau E, et al. Epigenetic alterations in disseminated neuroblastoma tumour cells: influence of TMS1 gene hypermethylation in relapse risk in NB patients. J Cancer Res Clin Oncol. 2010; 136:1415-1421. [PubMed: 20140741]

138. Yang Q, et al. Methylation of CASP8, DCR2, and HIN-1 in neuroblastoma is associated with poor outcome. Clin Cancer Res. 2007; 13:3191-3197. [PubMed: 17545522]

139. Decock A, Ongenaert M, Vandesompele J, Speleman F. Neuroblastoma epigenetics: from candidate gene approaches to genome-wide screenings. Epigenetics. 2011; 6:962-970. [PubMed: 21725203] 
140. Batora NV, et al. Transitioning from genotypes to epigenotypes: why the time has come for medulloblastoma epigenomics. Neuroscience. 2014; 264:171-185. [PubMed: 23876321]

141. Feinberg AP. The epigenetics of cancer etiology. Semin Cancer Biol. 2004; 14:427-432. [PubMed: 15489135]

142. Feinberg AP, Tycko B. The history of cancer epigenetics. Nat Rev Cancer. 2004; 4:143-153. [PubMed: 14732866]

143. Baylin SB. DNA methylation and gene silencing in cancer. Nat Clin Pract Oncol. 2005; 2 (Suppl 1):S4-S11. [PubMed: 16341240]

144. Gros C, et al. DNA methylation inhibitors in cancer: recent and future approaches. Biochimie. 2012; 94:2280-2296. [PubMed: 22967704]

145. McCabe MT, Creasy CL. EZH2 as a potential target in cancer therapy. Epigenomics. 2014; 6:341-351. [PubMed: 25111487]

146. Evans AE, et al. Effect of CEP-751 (KT-6587) on neuroblastoma xenografts expressing TrkB. Med Ped Oncol. 2001; 36:181-184.

147. Evans AE, et al. Antitumor activity of CEP-751 (KT-6587) on human neuroblastoma and medulloblastoma xenografts. Clin Cancer Res. 1999; 5:3594-3602. [PubMed: 10589776]

148. Ho R, et al. Resistance to chemotherapy mediated by TrkB in neuroblastomas. Cancer Res. 2002; 62:6462-6466. [PubMed: 12438236]

149. Iyer R, et al. Lestaurtinib enhances the antitumor efficacy of chemotherapy in murine xenograft models of neuroblastoma. Clin Cancer Res. 2010; 16:1478-1485. [PubMed: 20179224]

150. Minturn JE, et al. Phase I trial of lestaurtinib for children with refractory neuroblastoma: a new approaches to neuroblastoma therapy consortium study. Cancer Chemother Pharmacol. 2011; 68:1057-1065. [PubMed: 21340605]

151. De Braud FG, et al. Phase 1 open label, dose escalation study of RXDX101, an oral pan-trk, ROS1, and ALK inhibitor, in patients with advanced solid tumors with relevant molecular alterations [abstract]. J Clin Oncol. 2014; 32 (Suppl):a2502.

152. US National Library of Medicine. ClinicalTrials.gov [online]. 2014. http://clinicaltrials.gov/show/ NCT02122913

153. US National Library of Medicine. . ClinicalTrials.gov [online]. 2014. http://clinicaltrials.gov/ show/NCT02048488

154. US National Library of Medicine. ClinicalTrials.gov [online]. 2014. http://www.clinicaltrials.gov/ show/NCT01804530

155. Hsu LL, Evans AE, D’Angio GJ. Hepatomegaly in neuroblastoma stage 4s: criteria for treatment of the vulnerable neonate. Med Pediatr Oncol. 1996; 27:521-528. [PubMed: 8888811]

156. Kushner BH, Kramer K, LaQuaglia MP, Modak S, Cheung NK. Liver involvement in neuroblastoma: the Memorial Sloan-Kettering Experience supports treatment reduction in young patients. Pediatr Blood Cancer. 2006; 46:278-284. [PubMed: 16124002]

157. Yu AL, et al. Anti-GD2 antibody with GM-CSF, interleukin-2, and isotretinoin for neuroblastoma. N Engl J Med. 2010; 363:1324-1334. [PubMed: 20879881]

158. Louis CU, et al. Antitumor activity and long-term fate of chimeric antigen receptor-positive $\mathrm{T}$ cells in patients with neuroblastoma. Blood. 2011; 118:6050-6056. [PubMed: 21984804]

159. Baker DL, et al. Outcome after reduced chemotherapy for intermediate-risk neuroblastoma. $\mathrm{N}$ Engl J Med. 2010; 363:1313-1323. [PubMed: 20879880]

160. Yuza Y, Agawa M, Matsuzaki M, Yamada H, Urashima M. Gene and protein expression profiling during differentiation of neuroblastoma cells triggered by 13-cis retinoic acid. J Pediatr Hematol Oncol. 2003; 25:715-720. [PubMed: 12972807]

161. Shimada H, et al. The International Neuroblastoma Pathology Classification (the Shimada system). Cancer. 1999; 86:364-372. [PubMed: 10421273]

162. Fouladi M, et al. Pediatric phase I trial and pharmacokinetic study of vorinostat: a Children's Oncology Group phase I consortium report. J Clin Oncol. 2010; 28:3623-3629. [PubMed: 20606092]

163. Park, JR., et al. Advances in Neuroblastoma Research. Cologne; 2014. A phase I study of vorinostat in combination with isotretinoin (RA) in patients with refractory/recurrent 
neuroblastoma (NB): a new approaches to neuroblastoma therapy consortium trial [abstract]; $\mathrm{p}$. OR070

164. Simoes-Costa M, Bronner ME. Insights into neural crest development and evolution from genomic analysis. Genome Res. 2013; 23:1069-1080. [PubMed: 23817048]

165. Betancur P, Bronner-Fraser M, Sauka-Spengler T. Assembling neural crest regulatory circuits into a gene regulatory network. Annu Rev Cell Dev Biol. 2010; 26:581-603. [PubMed: 19575671]

166. De Preter K, et al. Human fetal neuroblast and neuroblastoma transcriptome analysis confirms neuroblast origin and highlights neuroblastoma candidate genes. Genome Biol. 2006; 7:R84. [PubMed: 16989664]

167. Tsarovina K, et al. Essential role of GATA transcription factors in sympathetic neuron development. Development. 2004; 131:4775-4786. [PubMed: 15329349]

168. Unsicker K, Huber K, Schober A, Kalcheim C. Resolved and open issues in chromaffin cell development. Mech Dev. 2013; 130:324-329. [PubMed: 23220335]

169. Pei D, et al. Distinct neuroblastoma-associated alterations of PHOX2B impair sympathetic neuronal differentiation in zebrafish models. PLoS Genet. 2013; 9:e1003533. [PubMed: 23754957]

170. Shimada H, et al. Histopathologic prognostic factors in neuroblastic tumors: Definition of subtypes of ganglioneuroblastoma and an age-linked classification of neuroblastomas. J Natl Cancer Inst. 1984; 73:405-413. [PubMed: 6589432]

171. Shimada $\mathrm{H}$, et al. International neuroblastoma pathology classification for prognostic evaluation of patients with peripheral neuroblastic tumors: a report from the Children's Cancer Group. Cancer. 2001; 92:2451-2461. [PubMed: 11745303]

172. Ambros IM, et al. Role of ploidy, chromosome 1p, and Schwann cells in the maturation of neuroblastoma. N Engl J Med. 1996; 334:1505-1511. [PubMed: 8618605]

173. Brodeur GM. Schwann cells as antineuroblastoma agents. N Engl J Med. 1996; 334:1537-1539. [PubMed: 8618612] 


\section{Review criteria}

We searched for original articles focusing on neuroblastoma regression in MEDLINE and PubMed published from 1971 to June 2014. In terms of potential mechanisms, we focused on articles that had been published in the past 15 years. The search terms used were "neuroblastoma" and one or more of the following: "regression", "spontaneous regression", "spontaneous differentiation", "telomerase", "regression and mechanisms", "regression and telomerase", "regression and TRK", "epigenetics", "immune function", "NK cells", "regression and immune". We also searched "genes" and "neural crest development" and "neuroblastoma and mass screening". All papers identified were English-language full-text papers. We also searched the reference lists of identified articles for further papers. 


\section{Key points}

- Neuroblastomas in younger children have a higher propensity to undergo spontaneous regression than any other human malignancy, but only genetic subtype 1 tumours with numerical chromosome aberrations are prone to spontaneous regression

- Although spontaneous regression of neuroblastoma is strongly associated with stage $4 \mathrm{~S}$ disease, mass-screening studies suggest that genetic subtype 1 tumours of any stage in infants $<18$ months can undergo spontaneous regression

- The TrkA/NGF pathway might have a major role in causing spontaneous regression, but alternative mechanisms might involve cellular or humoral immune responses, telomere shortening, or epigenetic modifications

- Inhibition of the TrkA pathway represents the most-promising approach to initiate regression in infants with favourable tumours; other approaches involving immune modulation or epigenetic regulation are being investigated 


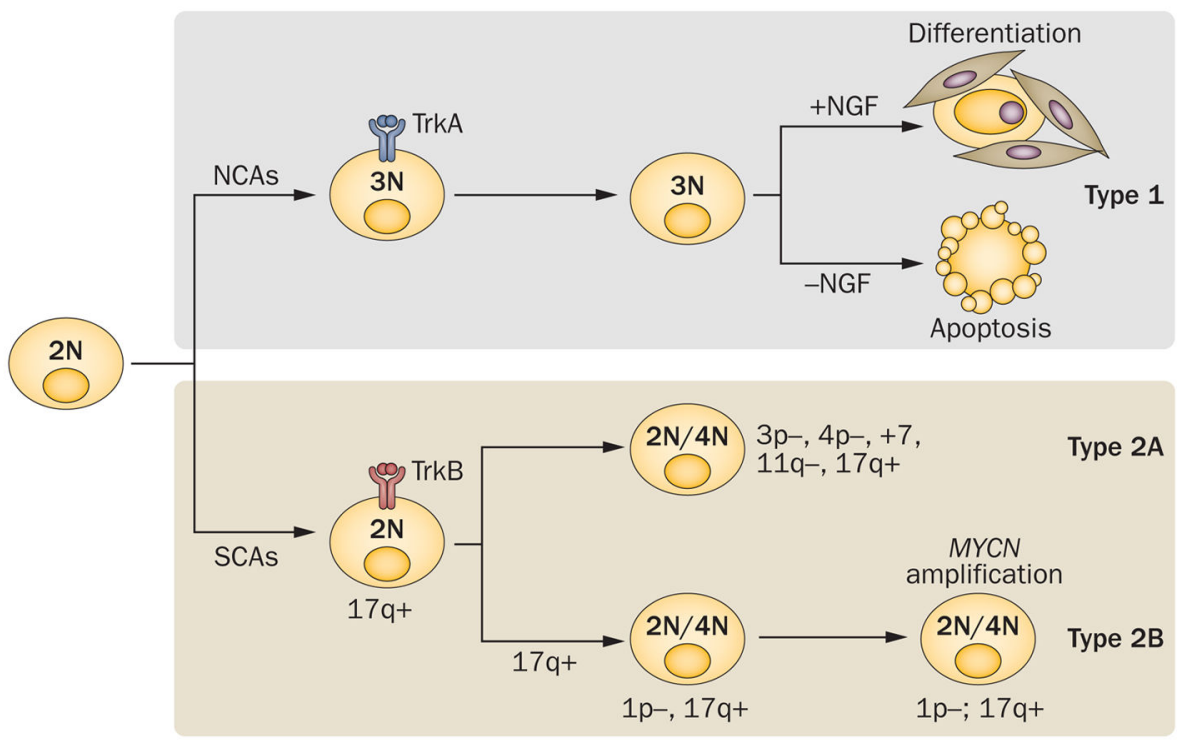

Figure 1.

Genomic model of neuroblastoma development. The major genomic pathways and genotype subsets of neuroblastoma are depicted here. Type 1 neuroblastomas have a favourable clinical outcome and consistently show numerical chromosome abnormalities (neartriploidy) without SCAs. They also have high expression of the TrkA neurotrophin receptor, and they are prone to undergo spontaneous regression (or differentiation), depending on the presence (+) or absence (-) of NGF in their microenvironment, respectively. Conversely, type 2 neuroblastomas are unfavourable clinically and are characterized by SCAs. Many of these tumours have unbalanced gain of chromosome 17q and express TrkB and BDNF. They can be separated into two subtypes based on additional genomic changes: type $2 \mathrm{~A}$ tumours also have selective regional loss of $3 \mathrm{p}, 4 \mathrm{p}$, and/or 11q, and many also have gain of chromosome 7; and type 2B have $M Y C N$ amplification, usually with $1 \mathrm{p}$ deletion, and they generally lack the additional changes found in type $2 \mathrm{~A}$. Type $2 \mathrm{~B}$ tumours are the most aggressive and rapidly progressive subtype. Abbreviations: BDNF, brain-derived neurotrophic factor; NGF, nerve growth factor; SCA, segmental chromosomal abnormalities. 
(1)

(2)

(2)

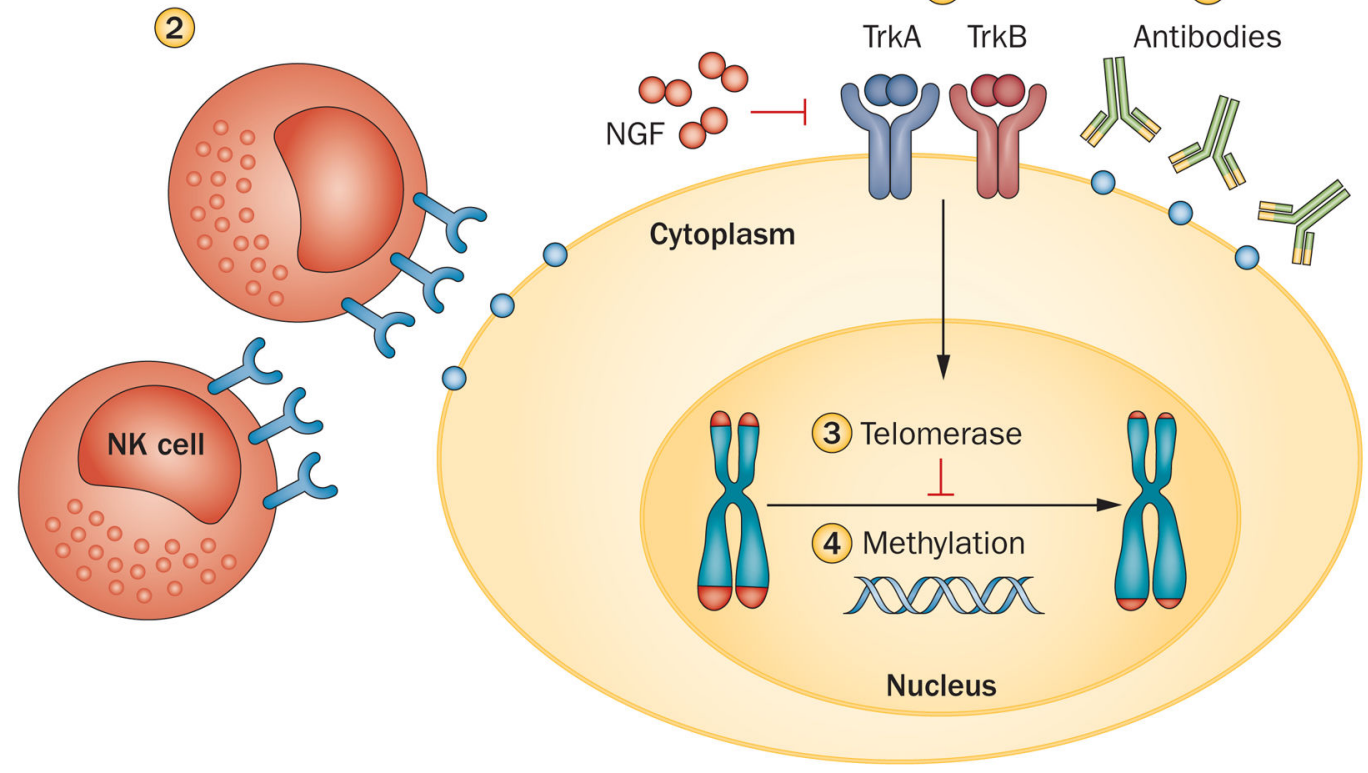

Figure 2.

Mechanisms of spontaneous regression. Shown are the major pathways that have been proposed to explain the phenomenon of spontaneous regression. These include: neurotrophin deprivation (TrkA without NGF) and activation of developmentally programmed apoptosis (1); immune-mediated cell killing by anti-neuroblastoma antibodies (and antibodydependent cellular toxicity) or by NK cells (2); telomere shortening and apoptosis triggered by low/absent levels of telomerase (3); and epigenetic changes in gene expression controlled by DNA methylation, histone modification, or alterations in chromatin remodelling (4). Abbreviations: NGF, nerve growth factor; NK, natural killer cells; TrkA, tropomyosin receptor kinase $\mathrm{A}$. 
Table 1

Somatically acquired mutations and rearrangements in neuroblastoma

\begin{tabular}{|lllll|}
\hline Gene & Function & Alteration & Frequency (\%) & Reference \\
\hline \multirow{2}{*}{ MYCN } & Transcription factor & Amplification & 22 & 15 \\
& & Activating mutation & 1.7 & 41 \\
\hline \multirow{2}{*}{ TLK } & Tyrosine kinase receptor & Activating mutation & 9.2 & 41 \\
& & Amplification/duplication & 3.4 & 41 \\
\hline PTPN11 & Tyrosine phosphatase & Activating mutation & 2.9 & 41 \\
\hline ATRX & Chromatin remodelling & Inactivating mutation & 2.5 & 42,44 \\
\hline ARIDIA/B & Chromatin remodelling & Inactivating mutation & $2-3$ & 43 \\
\hline NRAS & Signalling protein & Activating mutation & $\sim 1$ & 41 \\
\hline MLL-FOXR1, or PAFAH1B-FOXRI & Transcription factor & Translocation & 1.3 & 45 \\
\hline
\end{tabular}

